\title{
Application of Finite Difference Method and PSO Algorithm in Seismic Analysis of Narmab Earth Dam
}

\author{
Seyed Razi Anisheh \\ Expert on Golestan Regional Water Company, \\ Gorgan, Iran \\ Seyed Mahmoud Anisheh \\ Khaje Nasir Toosi University of Technology, \\ Tehran, Iran
}

\author{
Morteza Jiryaei Sharahi \\ Qom University of Technology, Qom, Iran
}

\author{
Mostafa Bastam \\ University of Mazandaran
}

\begin{abstract}
In this paper the dynamic behavior of the Narmab earth dam (Iran), considering dam-foundation interaction, under normalized Manjil earthquake as input motion has been studied. In order to assess the effect of the dam heights and the foundation widths, in the finite difference model on the earthquake response, various dam-foundation coupled models are analyzed by FLAC as finite difference program for solving mining and geotechnical engineering problems. In this research, a fitness function has been defined based on NonLinear Energy Operator (NLEO). The dam heights and the foundation widths has been chosen optimally using particle swarm optimization (PSO) method. The simulation results indicate considerable differences in the seismic responses.
\end{abstract}

\section{Keywords}

Dynamic analysis, Narmab earth dam, Manjil Earthquake, Non-Linear Energy Operator, particle swarm optimization

\section{INTRODUCTION}

The behavior of embankment dams, as one of the most important structures, under earthquake loading has attracted the attention of many researchers and dam designers. In the last decade, improvements in the different numerical methods have resulted in widespread use of these methods to study dynamic behavior of earth dams; and using dam-foundation coupled model has revealed various aspects of dam response to seismic shaking [1,2]. In simplified dynamic analyses of structures, it is normally assumed that the structure is fixed at the ground level and subjected to a base motion. The base motion represents the ground motion anticipated at the proposed site and is influenced by the nature and extent of the soil deposit at the site. In addition, the presence of the structure could also influence this base motion. This mutual influence of the structure and the foundation on their responses is commonly referred to as soil-structure interaction. When the response at the base of the structure is essentially identical to that with no structure present, there is no interaction between the soil and the structure. On the other hand, when the response at the base is significantly different for the two cases, strong interaction exists between the soil and the structure. For cases where the interaction is strong, the soil and structure systems should be analyzed together using a coupled system. For cases where the interaction is insignificant, the soil and structure systems can be uncoupled and each analyzed separately [3]. Earth dams on flexible foundations represent such a soil-structure system [3]. Very little work has been done regarding the seismic response of dams on flexible foundations. Most of the researches have been directed toward the analysis of dams on rigid foundations [3, 4, 5, 6, 7, 8, 9 and 10]. Ambraseys [11] extended previous work for dams on rigid foundations to dams on flexible foundations, but did not discuss the aspects of interaction. Chopra and Perumalswami [12] presented an analysis for dams on a semi-infinite medium subject to periodic excitations. Their studies covered both damping and the ratio of the elastic modulus of foundation soils to elastic modulus of the dam as they affect interaction. Wilson [13] utilized the finite element method to study the seismic response of an earth dam on a flexible foundation. The cases he presented indicated a high degree of interaction. Finn and Khanas [14] also evaluated the response of an earth dam on a flexible foundation using the finite element method of analysis. Their results indicated strong dependence of the response on the ratio of the fundamental periods of the dam and the foundation layer.

Finn and Reimer [15] considered the interaction problem between the dam and the underlying foundation layer. They analyzed both the coupled and the uncoupled dam-foundation systems and showed significant differences in the response depending on the period of the systems compared to the fundamental period of the base input motion. Seed et al. [3] showed that the interaction effects cannot be uniquely related to either the ratio of the period of the dam to the period of the foundation layer, or to the material properties of the dam and foundation layer. However, for the limited number of cases investigated, the interaction effects were found to be uniquely related to the ratio of the depth of the foundation layer to the width of the dam section.

Chopra et al. [16] by considering dam as an assemblage of two-dimensional finite elements, and the foundation as an elastic half space, determined the dynamic properties of earth dams including foundation interaction effects. Their results indicate that foundation interaction may have significant influence on the frequencies and mode shapes of vibration of earth dams and the influence of foundation interaction depends significantly on the geometry of the earth dam crosssection, being relatively more important for dams with flatter side slopes.

In this study dynamic analysis of Narmab earth dam (Iran) considering dam-foundation interaction, under Manjil earthquake (after scaling to a $\max =0.28 \mathrm{~g}$ ), as input motion, carried out by FLAC. In order to study the effect of the dam height and foundation width in the finite element model, on the calculated earthquake responses, several dam-foundation coupled models have been solved with FLAC. In addition, 
dam heights and the foundation width affect on the displacement of the dam. In order to measure displacement of dam, we have used a nonlinear energy operator (NLEO). In this research, NLEO has been defined as a function of both dam heights and the foundation width. We minimize the cost function using PSO algorithm.

This paper is organized as follows: The Narmab earth dam properties are described in Section 2. Section 3 presents the the numerical modeling for the dynamic analyses. The theoretical foundation of NLEO and PSO have been presented in Section 4. The performance evaluation of the proposed method are provided in Section 5. Section 6 summarizes our conclusions.

\section{NARMAB EARTH DAM}

Narmab earth dam, which is under construction, is located $120 \mathrm{~km}$ north east of Gorgan-Iran. It is constructed on the route of the Narmab River to supply agricultural and drinking water. It's height is $60 \mathrm{~m}$ from the foundation and with crest length of $807 \mathrm{~m}$. Fig. 1 shows typical cross section of the dam-foundation coupled model. The dam site is located in Alborz seismic zone where active periods have been observed. One of the most important earthquakes that occurred in this area, was the 1990 Manjil earthquake, with $\mathrm{Mb}=7.3$ and $\mathrm{Ms}=7.7$.

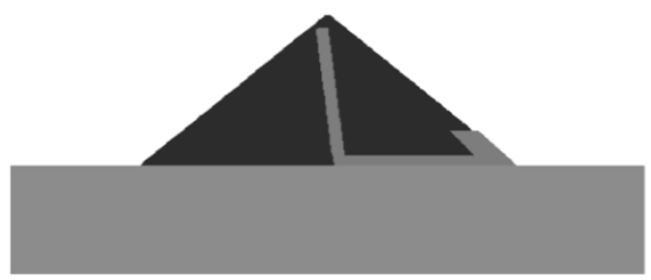

Fig 1:

Typical section of the dam-foundation coupled model

\section{DYNAMIC ANALYSIS}

The numerical modeling for the dynamic analyses has been performed using the FLAC, which is based on finite difference method. Among the geotechnical software, Quad4, Plaxis and Flac can be used to seismic analysis of the damfoundation model considering foundation-structure interaction. Quad4 is a dynamic, time-domain, equivalent linear two dimensional computer program to evaluate the seismic response of soil structures. Plaxis with dynamic module can be used to model advanced constitutive behaviors for the simulation of the non-linear, time dependent and anisotropic behavior of soils and/or rock. FLAC is a twodimensional explicit finite difference program for solving mining and geotechnical engineering problems. The program simulate the behavior of soils, structures built on soil, rock or other materials that may undergone plastic flow when their yield limits are reached. Materials are represented by elements, or zones, which form a grid that is adjusted by the user to fit the shape of the object to be modeled. Each element behaves according to a prescribed linear or non-linear stress/strain law in response to the applied forces or boundary restraints. The material can yield and flow, and the grid can deform in small and large-strain mode and move with the material that is represented. The explicit, Lanrangian calculation scheme and the mix-discretization zoning technique used in FLAC ensure that plastic collapse and flow are modeled accurately. Because no matrices are formed, large two-dimensional calculations can be made without excessive memory requirements. Several built-in constitutive models are available that permit the simulation of highly nonlinear, irreversible response representative of geologic, or similar materials. In addition, FLAC contains many special features such as interface elements, groundwater and consolidation models, structural elements, dynamic and viscoelastic (creep) analysis capabilities. It also contains the powerful built-in programming language FISH with which the users can write their own functions to extend FLAC's usefulness and even implement their own constitutive models.

Dynamic analyses were performed for the end of construction stage using the elasto-plastic Mohr-Coulomb model for material nonlinear behavior. Material properties of dam body and foundation have been presented in Table 1. In order to absorb the increments of stresses on the boundaries caused by dynamic loading, absorbent boundaries have been used.

Table 1.

Material properties of the Narmab earth dam

\begin{tabular}{|c|c|c|c|c|c|}
\hline $\begin{array}{c}\text { Type of } \\
\text { material }\end{array}$ & $\begin{array}{c}\gamma \\
(\mathrm{KN} / \mathrm{m} 3)\end{array}$ & $\begin{array}{c}\mathrm{C} \\
(\mathrm{KPa})\end{array}$ & $\varphi$ & $\begin{array}{c}\mathrm{E} \\
(\mathrm{MPa})\end{array}$ & $v$ \\
\hline Dam body & 21 & 27 & 22 & 214.6 & 0.3 \\
\hline Foundation & 21 & 1 & 42 & 267 & 0.3 \\
\hline $\begin{array}{c}\text { Drain } \\
\text { material }\end{array}$ & 20.7 & 1 & 42 & 348 & 0.25 \\
\hline
\end{tabular}

It should be mentioned that shear modulus, $G$ has been modified according to effective mean stress $\left(\sigma_{0}\right)$ as

$$
G=G_{i} \sqrt{\frac{\sigma_{0}}{\sigma_{0 i}}}
$$

Small viscous damping is added for dam body. This damper was given by Rayleigh damping: the damping factors were assumed 0.005 for the first and second natural periods.

Earthquake response analyses were carried out for Manjil earthquake. The acceleration time histories of the Manjil Earthquake as shown in Fig. 2, were normalized to a maximum acceleration of $0.28 \mathrm{~g}$ which has been considered inaccordance with Maximum Design Level (MDL).

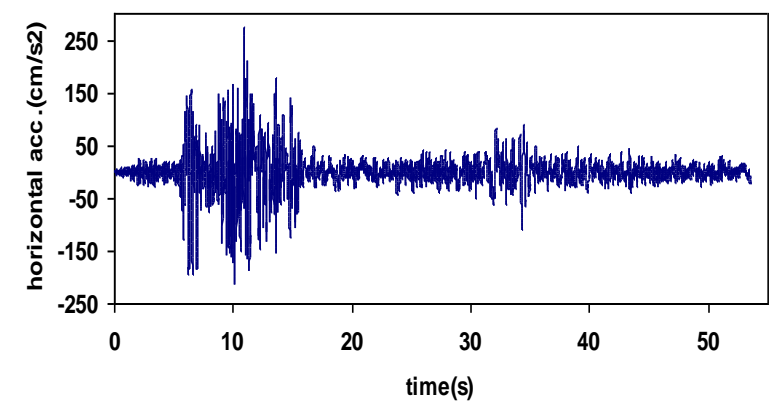

Fig 2:Normalized horizontal component time history of Manjil earthquake 


\subsection{NLEO}

In [17] a simple Non-Linear Energy Operator (NLEO) $\psi_{\mathrm{d}}$ has been proposed given here in its discrete form as

$$
\psi_{\mathbf{d}}[x(n)]=x^{2}(n)-x(n-1) x(n+1)
$$

By using simulated signals, Kaiser [17] analyzed this operator and found that it can detect frequency and amplitude of these signals. One of its key properties for a pure tone can be summarized by the rule

$$
Q_{d}(n)=\psi_{d}\left[A \operatorname{Cos}\left(\omega_{0} n+\theta\right)\right]=A^{2} \operatorname{Sin}^{2} \omega_{0}
$$

The proven can be expressed as:

$$
\begin{aligned}
& Q_{d}(n)=\psi_{d}\left[A \cos \left(\omega_{0} n+\theta\right)\right]=A^{2} \cos ^{2}\left(\omega_{0} n+\theta\right) \\
& -A \cos \left(\omega_{0}(n-1)+\theta\right) * A \cos \left(\omega_{0}(n+1)+\theta\right)= \\
& \frac{A^{2}}{2}\left[1+\cos \left(2 \omega_{0} n+2 \theta\right)\right]-\frac{A^{2}}{2} \cos \left(2 \omega_{0} n+2 \theta\right)- \\
& \frac{A^{2}}{2} \cos \left(2 \omega_{0}\right)=\frac{A^{2}}{2}-\frac{A^{2}}{2} \cos \left(2 \omega_{0}\right)= \\
& \frac{A^{2}}{2}\left[1-\cos \left(2 \omega_{0}\right)\right], 1-\cos \left(2 \omega_{0}\right)=2 \sin ^{2} \omega_{0} \\
& \Rightarrow Q_{d}(n)=\psi_{d}\left[A \cos \left(\omega_{0} n+\theta\right)\right]= \\
& \frac{A^{2}}{2} * 2 \sin ^{2} \omega_{0}=A^{2} \sin ^{2} \omega_{0}
\end{aligned}
$$

For $\omega_{0}$ much less than the sampling frequency, $Q_{d}(n)=A^{2} \omega_{0}{ }^{2}=c t e$. Therefore, The output of NLEO is proportional to multiplication of instantaneous amplitude and frequency of the input signal.

With the above motivation, Kaiser [17] used the second order differential equation governing the simple harmonic motion and the energy (sum of the kinetic and potential energies) required to generate the motion, to introduce a continuoustime counterpart of the NLEO,

$$
\psi_{C}[x(t)]=\left(x^{\prime}(t)\right)^{2}-x(t) x^{\prime \prime}(t)
$$

The instantaneous energy, $E_{0}$, of an undamped oscillator is constant and is proportional to the output of (3) [4].

$$
\psi_{C}[x(t)]=A^{2} \omega_{0}^{2} \propto E_{0}=\frac{m}{2} A^{2} \omega_{0}^{2}
$$

where $x(t)=A \operatorname{Cos}\left(\omega_{0} t+\theta\right)$ with $\left.\omega_{0}=\sqrt{(\mathrm{k} / \mathrm{m})}\right)$ is the displacement of the oscillator and $k$ is the spring constant and $m$ is the mass. Kaiser gave an interpretation of (6) as the amount of energy required to generate a sinusoid. Unlike the classical mean-square error (mse) definition of energy, this definition depends not only on the amplitude but also on the frequency of the sinusoid. To illustrate this difference, consider two sinusoids with frequencies of $1 \mathrm{~Hz}$ and $1 \mathrm{kHz}$ but with the same amplitude [18]. It is clear that mse energy will be the same for both sinusoids, while (6) suggests different amounts of energy requirement to generate these two signals. The latter relates the energy to the physics of generating a sinusoid of a given frequency [18]. As such, we will refer to the output of the NLEO (6) as the frequency weighted energy (FWE).

\subsection{PSO}

The basic operational principle of the particle swarm is reminiscent of the behavior of a group of a flock of birds or school of fishes or the social behavior of a group of people [19]. Each individual flies in the search space with a velocity which is dynamically adjusted according to its own flying experience and its companions' flying experience, instead of using evolutionary operators to manipulate the individuals like in other evolutionary computational algorithms. Each individual is considered as a volume-less particle (a point) in the N-dimensional search space. At time step t, the $i^{\text {th }}$ particle is represented as $X_{i}(t)=\left(x_{i 1}(t), x_{i 2}(t), \ldots, x_{i N}(t)\right)$. The set of positions of $m$ particles in a' multidimensional space is identified as $X=\left\{X_{1}, \ldots, X_{j}, \ldots, X_{l}, \ldots, X_{m}\right\}$. The best previous position (the position giving the best fitness value) of the $i^{\text {th }}$ particle is recorded and represented as $P_{i}(t)=\left(p_{i 1}, p_{i 2}, \ldots, p_{i N}\right)$.The index of the best particle among all the particles in the population (global model) is represented by the symbol $g$. The index of the best particle among all the particles in a defined topological neighborhood (local model) is represented by the index subscript $l$. The rate of the position (velocity) for particle $i$ at the time step $t$ is represented as $V_{i}(t)=\left(v_{i 1}(t), v_{i 2}(t), \ldots v_{i N}(t)\right)$. The particle variables are manipulated according to the following equation (global model [20]):

$$
\begin{aligned}
& v_{\text {in }}(t)=w_{i} * v_{\text {in }}(t-1)+c_{1} * \operatorname{rand} 1() * \\
& \left(p_{\text {in }}-x_{\text {in }}(t-1)\right)+c_{2} * \operatorname{rand} 2() *\left(p_{g n}-x_{\text {in }}(t-1)\right)
\end{aligned}
$$

where $n$ is the dimension $(1 \leq n \leq N), c_{1}$ and $c_{2}$ are positives constants, $\operatorname{rand} 1()$ and $\operatorname{rand} 2()$ are two random functions in the range [0,1], and $w$ is the inertia weight. For the neighborhood (lbest) model, the only change is to substitute $p_{\ln }$ for $p_{g n}$ in equation for velocity. This equation in the global model is used to calculate a particle's new velocity according to its previous velocity and the distance of its current position from its own best experience (pbest) and the group's best experience (gbest). The local model calculation is identical, except that the neighborhood's best experience is used instead of the group's best experience.

The constants $c_{1}$ and $c_{2}$ in above equation represent the weighting of the stochastic acceleration terms that pull each particle toward pbest and gbest positions. Thus, adjustment of these constants changes the amount of 'tension' in the system. Low values allow particles to roam far from target regions before tugged back, while high values result in abrupt movement toward, or past, target regions.

\section{RESULTS and DISCUSSIONS}

In order to evaluate the effects of dam height $(H)$ and foundation width $(B)$ (See Fig. 3) on the finite difference 
model, some experiments has been carried out in the finite difference model. On the basis of experiments, it had been found that foundation width must be selected less than twice the dam height in the finite element model [21]. Some possible values for $B$ and $H$ are demonstrated in Table 2. In this work an energy fitness function has been defined so that horizontal displacement time history at the dam crest in the finite difference model on the earthquake response is minimized. This function has been defined according to equation (2). The fitness function has been considered as a function of $B / H$ ratio and we minimize the cost function using PSO algorithm.

In this experiment, the following PSO parameters are used:

Population size: 30 ; Weight $_{\max }=1$; Weight $_{\min }=0.4 ; \mathrm{C} 1=\mathrm{C} 2=2$; Dimension=2; Iteration: $1000 . B$ and $H$ parameters change between 50-200 and 30-90, respectively. The PSO algorithm were implemented using MATLAB from Math Works. In this experiment, by using the PSO algorithm the $B / H$ ratio should be equal to 1.29. In fact, this paper proposes new approach for choosing $B$ and $H$ parameters using optimization techniques. However, these parameters were chosen empirically in the existing method [21].

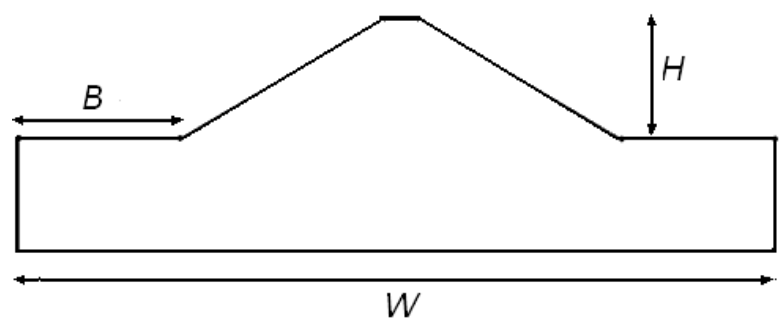

Fig 3:

Dam height $(H)$ and foundation width $(B)$ on the finite difference solution,

TABLE 2.

Desired Dam Heights Lateral Extents And Foundation Width

\begin{tabular}{|c|c|c|c|}
\hline Model Number & H (m) & B (m) & W (m) \\
\hline 1 & 30 & 50 & 303 \\
\hline 2 & 30 & 100 & 403 \\
\hline 3 & 30 & 200 & 603 \\
\hline 4 & 60 & 50 & 498 \\
\hline 5 & 60 & 100 & 598 \\
\hline 6 & 60 & 200 & 798 \\
\hline 7 & 90 & 50 & 669 \\
\hline 8 & 90 & 100 & 769 \\
\hline 9 & 90 & 200 & 969 \\
\hline
\end{tabular}

\section{CONCLUSION}

In this study, dynamic analysis of Narmab earth dam (Iran) considering dam-foundation coupled model with various foundation widths and dam heights under horizontal component of Manjil earthquake has been performed using the FLAC program. In the previous work, $B / H$ ratio has been adjusted experimentally. But, in this research it has been found optimally using PSO algorithm. Several experiments has been carried out and the results shown the efficiency of the proposed idea. In our experiment, by using the PSO algorithm the $B / H$ ratio should be adjusted as 1.29 .

\section{REFERENCES}

[1] Baziar, M.H., Merrifield, C.M., Salemi, Sh. and Heidari, T. 2004. Three dimensional dynamic analysis of alborz dam with asphalt and clay cores, Proc. of 5th International Conference on Case Histories in Geotechnical Engineering, USA, 13-17.

[2] Baziar, M.H., Noorzad, A, Salemi, Sh. and Ghannad, Z. 2003. Evaluation of Earthquake response of 15th Khordad Earth Dam, Proc. of the 21st ICOLD International Congress, 1011-1024

[3] IDRISS, I. M., MATHURT, J. M., BOLTON SEED, H. 1966. Earth dam-foundato interaction during earthquakes, Earthquake engineering and structural dynamics, 2, 313-323.

[4] Ambraseys, N. N. 1960. The seismic stability of earth dam, Proc. 2nd Wld Con\$ Earthquake Engng, 11, Tokyo, Japan, 1345-1363.

[5] Latifi, N., Marto, A. BT. 2011. Monitoring Results of Alborz Earth Dam during Construction, International Journal of Earth Sciences and Engineering, Volume 04, No 06 SPL, 1035-1039.

[6] Chopra A. K. and Clough, R. W. 1965. Earthquake response of homogeneous earth dams, Report No. TE 6511, Soil Mechanics and Bituminous Materials, Res. Lab., Dept. Ciu. Engng, University of California, Berkeley, 1122.

[7] Clough, R. W. and Chopra, A. K. 1966. Earthquake stress analysis in earth dams, J. Engng Mech. Div., ASCE, 92, No. EM2, 197-211.

[8] Martin, G. R. and Seed, H. B. 1965. Dynamic response analyses for earth dams, Report No. TE-65-1, Soil Mechanics and Bituminous Materials, Res. Lab. Dept. Civ. Engng, University of California, Berkeley, 25-58.

[9] Mononobe, N., Takata A., and Matumura, M. 1936. Seismic stability of the earth dam, Proc. 2nd Congress on Large Dams, IV, Washington, D.C. 45-56.

[10] Seed, H. B. and Martin, G. R. 1966. The seismic coefficient in earth dam design, J. Soil Mech. Fndn Diu., ASCE, 92, No. SM3, 1-48.

[11] Ambraseys, N. N. 1960. On the shear response of a two dimensional truncated wedge subjected to an arbitrary disturbance. Bull. Seis. Soc. Am. 50, 45-56.

[12] Chopra A. K., and Permulaswami, P. R. 1969. Dam foundation interaction during earthquakes, Proc. 4th Wld Conf. Earth-quake Engng, 11, Santiago, 313-323.

[13] Wilson, E. L. 1969. A method of analysis for the evaluation of foundation structure interaction, Proc. 4th Wld Con. Earth-quake Engng, 11, Santiago, 87-150.

[14] Finn, W. D. L. and Khanna, J. 1966. Dynamic response of earth dams, Proc. 3rd Symp. Earthquake Engng, University of Roorkee, U.P., 315-324.

[15] Finn, W. D. L. and Reimer, R. B. 1970. Effect of soil structures interaction on seismic response, Soil Mech. 
Series, Brit. Columbia. Univ., Dept of Civil Engineering Earthquake, Vancouver, 535-541.

[16] Chopra, A. K. and Perumalswami, P. R. 1971 .Dynamics of Earth Dams with Foundation Interaction, Journal of the Engineering Mechanics Division, Vol. 97, No 2. 181-191.

[17] Kaiser, J. F. 1990. On a simple algorithm to calculate the energy of a signal, in Proc. IEEE Int'l Conf. Acoust., Speech, and Sagnal Processing. 3-6.

[18] Agarwal, R. and Gotman J. 1999. Adaptive Segmentation of Electroencephalographic Data Using a Nonlinear Energy Operator, Proc. IEEE International
Symposium on Circuits and Systems (ISCAS'99), 4, 199202.

[19] Eberhart, R. C. and Kennedy, J. 1995. A new optimizer using particle swarm theory, Proc. ISMMHS, 39-43.

[20] Shi, Y.and Eberhart, R. C. 1999. A Modified Particle Swarm Optimizer, in Proc. IJCNN, 69-73.

[21] JIRYAEI SHARAHI, M. and Anisheh, S. R. 2010. Seismic Analysis of Narmab earth dam IRAN) considering dam foundation interaction, ICOLD Conference, Vietnam, 1-4. 